\title{
Expression Profiling of Glycoprotein D Gene of Bovine Herpes Virus in Madindar by Bovine Kidney Cells via Real Time PCR
}

\author{
Asmita Singh* and Ajay Kumar \\ Animal Nutrition Division, ICAR-Indian Veterinary Research Institute, \\ Bareilly, UP, 243122, India \\ *Corresponding author
}

\begin{tabular}{|c|}
\hline Keywords \\
\hline $\begin{array}{l}\text { Glycoprotein D, } \\
\text { Expression, } \\
\text { Alphaherpes } \\
\text { viruses, Herpes } \\
\text { viridae }\end{array}$ \\
\hline Article Info \\
\hline $\begin{array}{l}\text { Accepted: } \\
\text { 20 September } 2018 \\
\text { Available Online: } \\
10 \text { October } 2018\end{array}$ \\
\hline
\end{tabular}

A B S T R A C T

Bovine herpesvirus-1 (BHV-1) a member of the Herpes viridae family and Alphaherpes viridae subfamily genus Varicello virus is a most common viral pathogen found in bovine semen. The entry process of Alphaherpes viruses consist of two steps, initial virus attachment and subsequent virus penetration involving membrane fusion as in other alphaherpes viruses, BHV-1 glycoproteins are the major structural components of the viral envelope and virus-infected cell membranes. Glycoprotein $\mathrm{D}(\mathrm{gD})$, of BHV-1 is one of four major glycoproteins, namely $\mathrm{gB}, \mathrm{gC}, \mathrm{gD}$, and $\mathrm{gH}$ that have been identified on the virus envelope and the plasma membranes of BHV-1-infected cells [14, 24]. Total of 73 open reading frames (ORFs) have been clearly identified which are homologous to genes found in other alpha herpes viruses. The BHV-1 genome encloses ten genes encoding the glycoproteins, among them, six genes are in the UL region, namely gK (UL 53), gC (UL 44), gB (UL 27), gH (UL 22), gM (UL 10), gL (UL 1) and four remaining genes are in the Us region, gG (US 4), gD (US 6), gI (US 7) and gE (US 8). In the present study, a time course expression profile analysis of gD (US 6), was carried out at at $6 \mathrm{hr}, 12 \mathrm{hr}, 24 \mathrm{hr}$ of $\mathrm{h}$ post infection quantitative RT-PCR RT-PCR as well as Real Time PCR. Gapdh was used as reference control to normalize the expression levels. A significant decrease in $\mathrm{gD}$ expression at $3 \mathrm{~h}$ post infection (h.p.i) was observed followed by an increase in between 6 hr to $12 \mathrm{hr}$ h.p.i. Expression of gC gene become static in between 12 to $24 \mathrm{hr}$. However, further studies need to be carried out to unfold the molecular mechanism of interaction between host and virus to devise efficient control strategies for this chaos in the virus infection.

\section{Introduction}

The dairy sector has played a very vital role in the economic development of India through 63 years of Independence. India now produces 102.9 million tons of milk (FAO, 2007), world's largest milk producing country. To this, buffaloes contribute 55\% and cattle $45 \%$ of total milk production. With the introduction of cross-breeding programs, these animals have become susceptible to many diseases like Infectious bovine rhino-tracheitis /infectious pustularvulvo-vaginitis (IBR/IPV), caused by Bovine Herpes Virus-1 (BHV-1). Bovine herpesvirus-1 (BHV-1) a member of the Herpes viridae family and Alphaherpes viridae subfamily genus Varicello virus is a most common viral pathogen found in bovine 
semen. BHV-1 virion is enveloped containing an icosahedral capsid surrounded by tegument, replicates in the nucleus but the envelope is acquired while budding through nuclear membrane. It is an important pathogen of cattle causing two major clinical syndromes, namely known as Infectious Bovine Rhinotracheitis (IBR) and Infectious Pustular Vulvovaginitis (IPV) (Kit et al., 1989; Wyler et al., 1989; Tikoo et al., 1995). A total of 73 open reading frames (ORFs) have been clearly identified which are homologous to genes found in other alpha herpes viruses. The BHV1 genome encloses ten genes encoding the glycoproteins, among them, six genes are in the UL region, namely gK (UL 53), gC (UL 44), gB (UL 27), gH (UL 22), gM (UL 10), gL (UL 1) and four remaining genes are in the Us region, $\mathrm{gG}$ (US 4), gD (US 6), gI (US 7) and gE (US 8). BHV-1 infection of permissive cells is initiated first by the low affinity interaction between viral $\mathrm{gB}$ and/or $\mathrm{gC}$ to the cell surface structures like heparin sulfate sugar moieties ( $\mathrm{Li}$ et al., 1995). This is followed by the stable binding of BHV-1 gD to cellular specific receptor and subsequent virus penetration by fusion of the virion envelop with the plasma membrane (Liang et al., 1989).

The entry process of alpha herpes viruses consists of two steps, initial virus attachment and subsequent virus penetration involving membrane fusion. Glycoprotein $\mathrm{D}(\mathrm{gD})$ of the BHV -1 is an essential envelope protein, and it has been previously documented that $\mathrm{gD}$ plays a significant part in the virus entry steps (Liang et al., 1997). Glycoprotein $\mathrm{D}(\mathrm{gD})$ of BHV-1 has been shown to be an essential component of virions involved in virus entry (Babiuk et al., 1996). gD expression in infected cells is also required for direct cell-tocell spread (Schroder et al., 1997).

The first interaction involves low affinity virus attachment between $\mathrm{gB}$ and /or $\mathrm{gC}$ to cell surface structures like heparan sulfate sugar moieties. This is followed by the stable binding of BHV-1 $\mathrm{gD}$ to cellular specific receptors. After this high affinity interaction between $\mathrm{gD}$ and cell receptors, the subsequent virus penetration occurs by fusion of the virion envelope with plasma membrane. This crucial process requires at least the involvement of four glycoproteins $\mathrm{gD}, \mathrm{gB}$ and the heterodimer formed by $\mathrm{gH}$ and $\mathrm{gL}$ (B. Muylkens et al, 1995). Live but also inactivated BHV-1 induced PBMC apoptosis suggested that a structural component of BHV-1 has the capacity to activate the apoptotic process. Moreover, only the attachment of BHV-1 was able to induce programmed cell death. Glycoprotein D was shown to be involved in this BHV-1, induced apoptosis (Hanon et al., 1996).

These glycoproteins, of which $\mathrm{gB}, \mathrm{gC}$, and $\mathrm{gD}$ have been identified as the major immunogens recognized by sera from infected cattle (Collins et al., 1985, van Drunen Little- van Hurk and Babiuk, 1986; Marshal et al., 1986). Glycoproteins $\mathrm{gB}$ and $\mathrm{gD}$ are essential for virus replication and are responsible for inducing neutralizing antibody responses in the host. Although $\mathrm{gC}$ is dispensable for replication and induces lower neutralizing antibody response, it is immunodominant and is believed to play a role in initial attachment (reviewed in Tikoo et al., 1995) These properties make the three proteins excellent target antigens for detection and analysis of BHV-1 immune responses. All of these factors make it important to develop diagnostics and vaccines, unless they are based on molecular techniques

Understanding the role of glycoprotein D gene in interaction between the cell and virus at molecular level would greatly help us in formulating effective therapeutic strategies. Hence a study was conducted on the expression profiles of the gc gene (US6 region 
of open reading frame) containing proteins glycoprotein D in BHV -1 infected MDBK cells.

\section{Materials and Methods}

\section{MDBK culture}

Madin - Darby Bovine Kidney (MDBK) cell line was kindly provided by NCCS Pune. This cell line was maintained in DMEM supplemented with $100 \mathrm{U} / \mathrm{ml}$ penicillin and $100 \mathrm{~g} / \mathrm{ml}$ streptomycin and $10 \%$ fetal calf serum in $25 \mathrm{sq} \mathrm{cm}$ flask. This cell was used for propagation of $\mathrm{BHV}-1$.

\section{Preparation of experimental culture plate}

MDBK cells were observed under microscope for confluence and then medium was decanted and monolayer was washed with serum free medium.1 ml trypsin-versene solution was added to the cells in 25 sq. cm flask and incubated at $37^{\circ} \mathrm{C}$ for $2 \mathrm{~min}$. The excess trypsin-versene was discarded and flask was re-incubated till cells started coming out from the monolayer. The cells were completely taken off from monolayer by gently flushing with pipette and growth medium containing $10 \%$ FCS was added and cells were dispersed equally in 24 well plate. The 24 well plate was incubated at $37^{\circ} \mathrm{C}$ till monolayer was formed

\section{Infection of virus in MDBK cell lines}

MDBK cell lines were full grown in $25 \mathrm{~cm}^{2}$ flask and we prepare a six well plate. After completion of complete monolayer in each well infect these cells by BHV-1 viruses. Add $100 \mu l$ of virus was infected into well and one with cell control. Virus was allowed to adsorb on the cells by incubating the flask at $37^{\circ} \mathrm{C}$ for $1 \mathrm{hr}$ with intermittent shaking after every 10 min. After adsorption, inoculum was discarded and $5 \mathrm{ml}$ maintenance medium containing 2\% FBS added and cells were incubated at $37^{\circ} \mathrm{C}$. There was cytopathic effect (CPE) after $24 \mathrm{hr}$. The virus infected cells were harvested at $6 \mathrm{hr}, 12 \mathrm{hr}, 24 \mathrm{hr}$ of h.p.i and preserved in $1 \mathrm{ml}$ of TRI-REAGENT (MRC) for isolation of total RNA. After completion of monolayer, the medium from plate was drained. The cell monolayer was washed once with maintenance medium and the cells were infected by adding $0.5 \mathrm{ml}$ of virus stock.

\section{Extraction of BHV-1 RNA from cell culture fluid}

Total RNA from infected and control cell culture fluid at different time points were isolated using TRIzol reagent (Invitrogen, USA) based on manufacturers' instructions after $3 \mathrm{hr}, 6 \mathrm{hr}, 12 \mathrm{hr}$, and $24 \mathrm{hr}$ of post infection. TRIzol reagent was used for lysis of monolayer in $25 \mathrm{~cm}^{2}$ flask. Around $1 \mathrm{ml}$ TRIzol reagent was added directly on monolayer and flushed with the help of pipette. Further, the following steps were carried out as follows: $200 \mu \mathrm{l}$ of chloroform was added and tube was vigorously vortexed for $2 \mathrm{~min}$ and incubated at room temperature for 10 minutes. Mixture was centrifuged at $10,000 \mathrm{rpm}$ for 10 minutes at $4^{\circ} \mathrm{C}$ for phase separation. Carefully, the upper aqueous phase was removed transferred into a new $1.5 \mathrm{ml}$ DEPC treated microcentrifuge tube.500 $\mu 1$ of isopropanol for 1.0 $\mathrm{ml}$ TRIzol reagent was added to the aqueous supernatant and mixed by upside down and incubated at room temperature for $10 \mathrm{~min}$ and was centrifuged at $12,000 \mathrm{rpm}$ for $10 \mathrm{~min}$ at $4^{\circ} \mathrm{C}$ for RNA precipitation. Supernatant was discarded and pellet was washed with $0.5 \mathrm{ml}$ of $75 \%$ ethanol and centrifuged at 7,500 rpm for $10 \mathrm{~min}$ at $4^{\circ} \mathrm{C}$. Finally, pellet was dried at $50^{\circ} \mathrm{C}$ for $10 \mathrm{~min}$ and re-suspended in $50 \mu \mathrm{l}$ DEPC treated water.

\section{cDNA synthesis}

The total RNA was quantified by measuring at $260280 \mathrm{~nm}$ in Nanodrop spectrophotometer. 
The ratio of A260 and A280 was calculated to check the purity of extracted RNA and quality was checked on a $1 \%$ agarose gel. Total RNA was treated with RNase free DNase 1 (Fermentas, USA) to remove DNA contamination. The concentration of RNA was determined by Nanodrop spectrophotometer so that in cDNA synthesis taken same amount of RNA having same concentration which is measure by Nanodrop in order to prevent use of internal control. First strand cDNA synthesis was carried out using $1 \mu \mathrm{g}$ of DNase-treated total RNA as template. Reverse transcription was performed using Moloney leukemia virus reverse transcriptase (Fermentas, USA), Random hexamer primer $(0.2 \mu \mathrm{g} / \mu \mathrm{l}), 1 \times \mathrm{RT}$ reaction buffer, dNTPs $(10 \mathrm{mM}), 20 \mathrm{U}$ of ribonuclease inhibitor and 40 units of reverse transcriptase in a final reaction volume of $20 \mu \mathrm{l}$. The reaction was carried as per the manufacturers' instructions.

\section{Semi quantitative RT-PCR analysis}

Semi quantitative RT-PCR was performed using $50 \mu \mathrm{g}$ cDNA as template. The primers FP: 5'CCCGATGCCGCGATACAACT3', RP: 5'CGCACCCGCTCTCGATCTTG -3' were used to amplify glycoprotein $\mathrm{D}$ gene to generate $236 \mathrm{bp}$ fragments of $\mathrm{gC}$ gene of $\mathrm{BHV}-1 . \beta$ actin was used as internal control and was amplified with the primers pair The thermocycling parameters consisted of an initial denaturation at $94^{\circ} \mathrm{C}$ for 4 min followed by 30 cycles of $94^{\circ} \mathrm{C}$ for $30 \mathrm{~s}, 58^{\circ} \mathrm{C}$ for $45 \mathrm{~s}$ and $72^{\circ} \mathrm{C}$ for $1 \mathrm{~min}$. The final extension was done for $5 \mathrm{~min}$ at $72^{\circ} \mathrm{C}$. Hold temperature was set at $4^{\circ} \mathrm{C}$. The PCR products were run on $1.5 \%$ gels for further analysis. PCR products were quantified using Gene Tools Software.

\section{Real time PCR analysis}

Real-time PCR amplifications were carried out in Mx3000P spectroflourometric thermal cycler operated by MxPro TMQPCR software using SYBR Green (Fermentas, USA) chemistry. The same primer pairs used in Semi-quantitative RT-PCR were used to amplify both glycoprotein D gene and internal control $\beta$ actin.

The thermal profile used for PCR amplification consisted of initial denaturation at $95^{\circ} \mathrm{C}$ for $5 \mathrm{~min}$, followed by 40 cycles of denaturation at $95^{\circ} \mathrm{C}$ for $30 \mathrm{~s}$, annealing and extension at $58^{\circ} \mathrm{C}$ for $30 \mathrm{sec}$. Melting curve analysis of amplification products were performed at the end of each PCR reaction to confirm that only one PCR product was amplified and detected.

To assess the specificity of amplified product, dissociation curve were generated at temperature between $55^{\circ} \mathrm{C}$ and $95^{\circ} \mathrm{C}$ and the results was expressed in threshold cycle $(\mathrm{Ct}$ value).

Comparative CT method was used to estimate the relative expression of the target mRNA. Briefly, $\Delta \mathrm{CT}$ was calculated by subtracting CT value of internal control from target gene and then mean $\Delta \mathrm{CT}$ was calculated from this normalized $\Delta \mathrm{CT}$ value. $\Delta \Delta \mathrm{CT}$ was calculated with respect to control by, subtracting mean $\Delta \mathrm{CT}$ of control treatment from mean $\Delta \mathrm{CT}$ of the target gene. Fold change at various time intervals was calculated by $2-\Delta \Delta \mathrm{CT}$. EF1 $\alpha$ was selected as internal control for normalization.

\section{Statistical analysis}

The differences in transcript levels between different time intervals were tested for statistical significance using one-way ANOVA followed by Duncan's new multiple range test using the statistical package, (SAS Inc., USA) (Attwood et al., 2007; Alenjandro et al., 2008) p value below 0.05 was considered statistically significant. The results were expressed as the mean $\pm \mathrm{SD}$. 


\section{Results and Discussion}

\section{Semi quantitative analysis of $\mathrm{gD}$ gene in time course study}

The expression pattern of gD gene in BHV-1 infected cell line was investigated in a time course study. The expression pattern varied between different time intervals. Expression was observed lower in RT-PCR analysis in 0 to 3 h.p.i while increased expression was observed In between $6 \mathrm{hr}$ to $12 \mathrm{hr}$ expression. The expression showed an static trend from 12 to 24 h.p.i. (Figure 1). The expression pattern was compared with that of EF1 $-\alpha$, whose expression remained unchanged throughout the time period (Figure 2).

Real time expression profiles of glycoprotein D gene in MDBK cells of BHV-1 infected

Relative expression analysis of the glycoprotein D gene at different time points post BHV-1 infection was also studied by Real Time RT-PCR using SYBR green chemistry. B actin was used as the internal control. In Real time analysis it was observed that there was a tremendous increase in the expression of $\mathrm{gD}$ gene in between $6 \mathrm{hr}$ to 12 h.p.i. expression followed by a static expression at 24 h.p.i (Figure 3). A fold change of greater than 45000 fold was observed in the expression gD at 12 h.p.i. and then showed a gradual stability. The expression of EF1 $-\alpha$ remained same throughout the experimental period. Melt curve analysis of the genes showed a single peak for all the genes studied and expression levels were found to be statistically significant.

The BHV-1 genome encloses ten genes encoding the glycoproteins, among them, six genes are in the UL region, namely $\mathrm{gK}$ (UL 53), gC (UL 44), gB (UL 27), gH (UL 22), gM
(UL 10), gL (UL 1) and four remaining genes are in the Us region, gG (US 4), gD (US 6), gI (US 7) and gE (US 8).BHV-1 infection of permissive cells is initiated first by the low affinity interaction between viral $\mathrm{gB}$ and/or $\mathrm{gC}$ to the cell surface structures like heparin sulfate sugar moieties (Li et al., 1995). This is followed by the stable binding of BHV-1 gD to cellular specific receptor and subsequent virus penetration by fusion of the virion envelop with the plasma membrane (Liang et al., 1989). Glycoprotein $\mathrm{D}$ (gD), a major viral immunogen, is essential for virus replication and is responsible for inducing the strongest immune response, reducing virus replication and shedding by host. The $\mathrm{gD}$ gene is well studied and highly conserved among herpes viruses. It is located in the US region between map units 0.892 and 0.902 of the BHV-1 genome, encoding a 71 kilodalton (KDa) glycoprotein of 417 amino acids (aa), containing both $\mathrm{N}-$ and O-linked oligosaccharides (Chase and Letchworth, 1994, Tikoo et al., 1993). These properties of $\mathrm{gD}$ make it an excellent candidate for genetic characterization of the Egyptian vaccinal strain (Abu-hammad) of BHV-1.

As no reports were found on the functional aspects of $\mathrm{gD}$, the present study was designed to check whether the $\mathrm{gD}$ gene expression profiles in BHV challenged Mdbk cells The expression levels of glycoprotein D gene was quantified by normalizing with the expression of $\beta$ actin. The $\mathrm{gD}$ gene expression was observed at all the time points tested including the control i.e., the unchallenged group. The expression was almost constant till 3 h.p.i. while a significant increase was observed in between 6 to $12 \mathrm{~h}$ post infection (h.p.i). The expression static from 12 to 24h.p.i.A similar study by Hassan Momtaz1 and Mohammadreza Nazem, (2010) in in bacterial cell revealed that the expression of infectious bovine rhinotracheitis virus. According to them Bovine Herpesvirus 1 (BHV-1) belongs 
to the genus of Varicellovirus and the family of Herpesviridae which contains three main $\mathrm{gB}, \mathrm{gC}$ and $\mathrm{gD}$ genes. In order to cloning of the coding region of $\mathrm{gD}$ gene of IBR virus, PCR product of the open reading frame of the gene from IBR virus isolated in Iran was amplified by PCR. A 1047bp PCR product of the $\mathrm{gD}$ gene with EcoRI, HindIII restriction sites were subcloned of $\mathrm{pTZ} 57 \mathrm{R} / \mathrm{T}$ and digested by the mentioned endonucleases. Digested insert cloned in topET-32a and transfered in E. coli cells. For the expression of $\mathrm{gD}$ protein, the $\mathrm{pET}-32 \mathrm{a}$ recombinant vector was transformed and then induced in BL21 (DE3) strain of E. coli competent cells using IPTG. The presence of $\mathrm{gD}$ expressed protein was shown in immunoblotting and SDS-PAGE system. With respect to the remarkable frequency of infection to IBR in Iran and the necessity of controlling it through vaccination with recombinant vaccines of thymidine kinase, manufacturing and applying the recombinant $\mathrm{gD}$ protein are vital goals in recognition and distinction between infection and responses caused by vaccine.

The detection of viral infections may be based on direct or indirect diagnostic method. The development of molecular biology has contributed to the appearance of highly sensitive new diagnostic approaches. Various recombinant DNA techniques have been applied to the rapid detection of nucleic acid, used to study viral genes and also to produce new types of vaccines. PCR has been one of the most rapidly adopted techniques. Reports on the application of PCR to the diagnosis of infectious diseases are also accumulating at an exponential rate (Erlich et al., 1991; Pershing et al., 1991). Molecular virology has served to establish bovine herpes virus (BHV-1) as the prototype member of ruminant herpes viruses based on the genomic sequence of the virus.

The nucleotide sequence of the BHV-1 genome $(136 \mathrm{~kb})$ has completed by international cooperation (July 1995; it comprises 67 unique genes and 2 genes, both duplicated, in the inverted repeats. BHV-1 genome encodes approximately 73 proteins but only 54 transcripts have so far been identified in productive infection by northern blot analysis (Wirth et al., 1989). There are at least 10 glycoprotein with predicted molecular weights range from $17-101 \mathrm{kda}$. They are generally $\mathrm{N}-$ linked and $\mathrm{O}-$ linked glycosylation with homodimer and heterodimer forms. These virally encoded glycoproteins are gB (UL27), gC(UL44), gD (US8), $\quad \mathrm{gI}(\mathrm{US} 7), \quad \mathrm{gH}(\mathrm{UL} 22), \quad \mathrm{gL}(\mathrm{UL} 1)$, gG(US4), gK(UL53), gM(UL10). gB (UL27) contain 932 amino acids with MV $130 \mathrm{KDa}$ essential for attachment, entry, cell to cell spread and fusion (Byrne et al., 1995). $\mathrm{gC}$ contain 508 amino acids with MW $91 \mathrm{KDa}$ responsible for variable attachment (chase $e t$ al., 1993), gD(US6) with 417 amino acids with MW $71 \mathrm{KDa}$ essential for entry and cell to cell spread, gE (US7), 575 amino acids (MW $92 \mathrm{KDa}$ ) cell to cell spread and virulency. UL11, UL36, UL37, UL41, UL46, UL47, UL48, UL49 and US9 are the major tegumental proteins (Schwyzer et al., 1996). Capsid proteins are UL18, UL19, UL26, UL35 and UL38. DNA replication proteins are UL 29 (major DNA binding protein), UL30, ul42 (DNA polymerase), UL5, UL8, UL29 (helicase) (Geng et al., 1995).

Glycoprotein $\mathrm{D}(\mathrm{gD})$, a major viral immunogen, is essential for virus replication and is responsible for inducing the strongest immune response, reducing virus replication and shedding by host (34). The $\mathrm{gD}$ gene is well studied and highly conserved among herpesviruses. It is located in the US region between map units 0.892 and 0.902 of the BHV-1 genome, encoding a 71 kilodalton (KDa) glycoprotein of 417 amino acids (aa), containing both N- and O-linked oligosaccharides (Abdelmagid1 et al., 1998) (Fig. 4 and 5). 
Fig.1 gD gene expression at different time points post infection. Lane M: 100bp plus marker, Lane 1-4: h post infection $0,3,6,12,24$ h.p.i, respectively

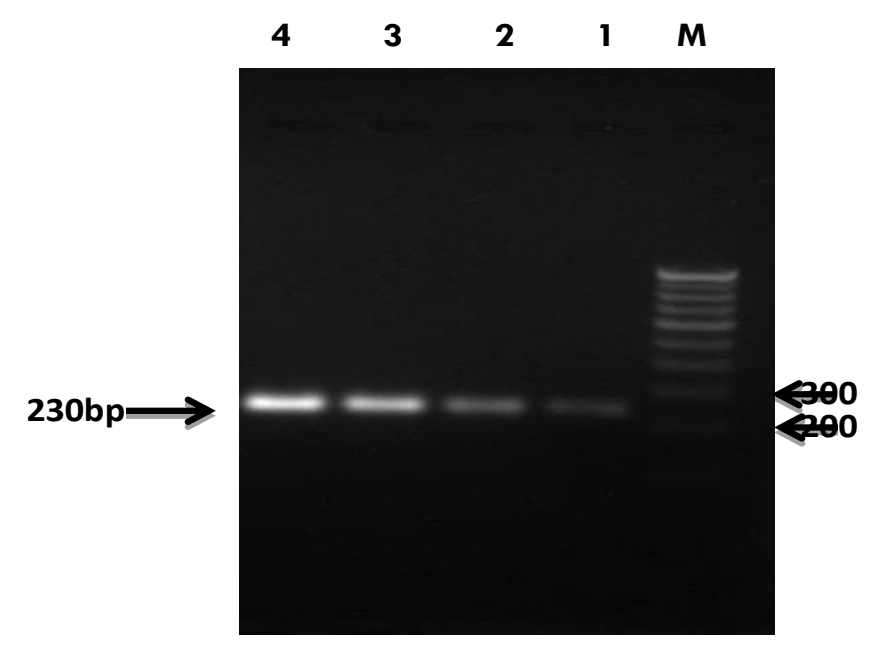

Fig. $2 \beta$ actin expression at different time points post infection. Lane M: 100bp plus marker, Lane 1-4: h post infection $0,3,6,12,24$ h.p.i, respectively

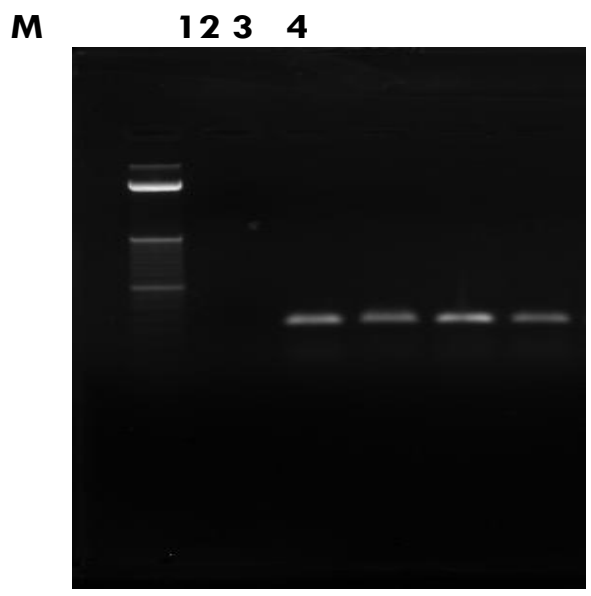

Fig.3 Amplification curve showing Expression profile of gD gene in MDBK cells after infection at different hours

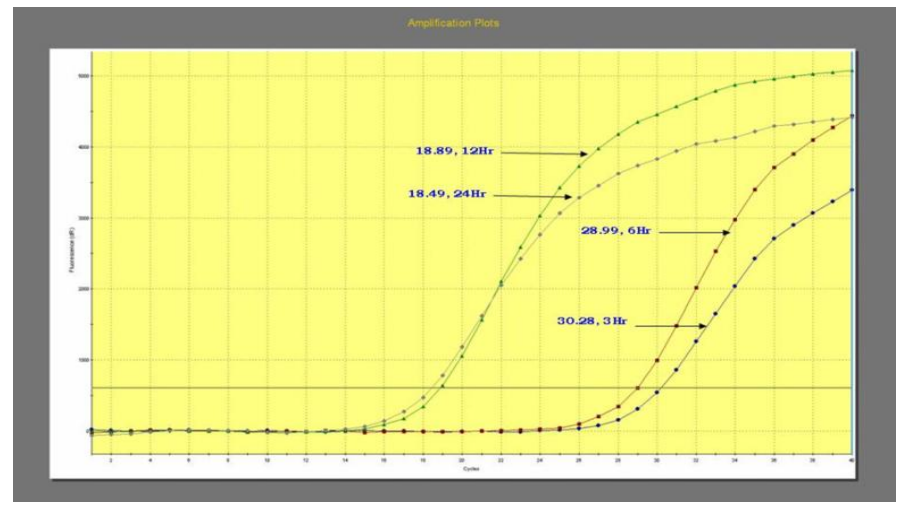


Fig.4 Dissociation curve showing specific amplification with a single peak

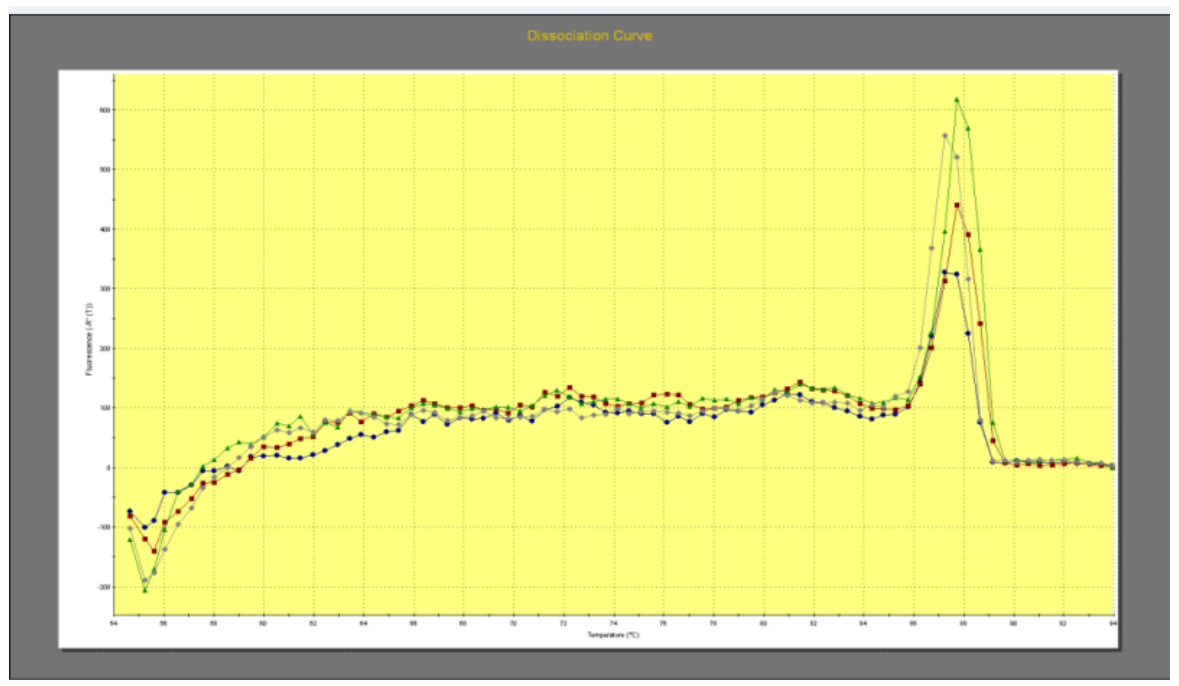

Fig.5 Fold changes (mean $\pm \mathrm{SD}$ ) in expression of $\mathrm{gD}$ gene in real time PCR

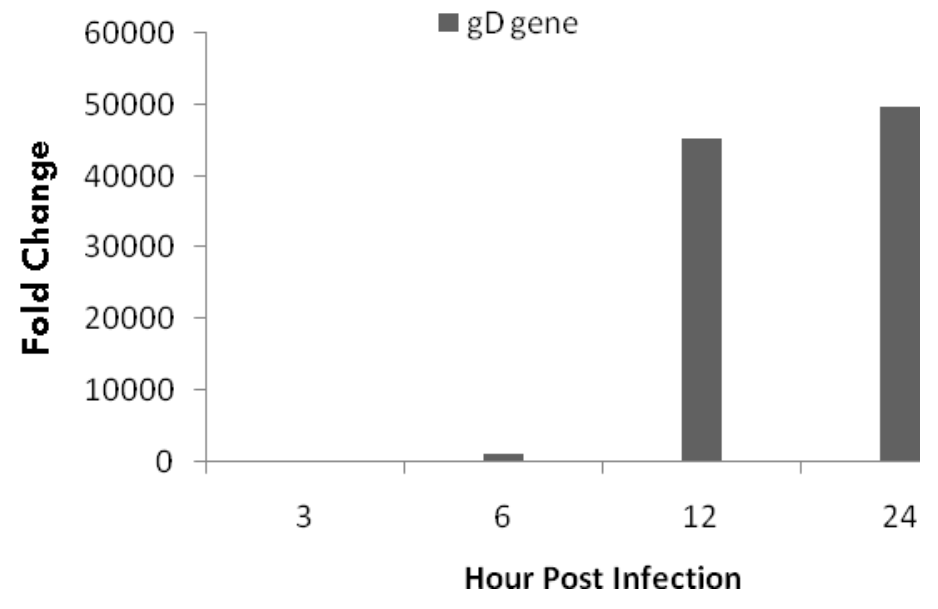

These properties of $\mathrm{gD}$ make it an excellent candidate for genetic characterization of the Egyptian vaccine strain (Abu-hammad) of BHV-1.because of their location in the virion envelope and on the surface of infected cells, the glycoproteins are important targets for the host immuneresponse. Furthermore, they play important roles in pathogenicity mediating entry of the virion into the host cellfusion, and cell -to-cell spread of virus Glycoprotein D (gD) of bovine herpesvirus 1 (BHV-1), a homolog of herpes simplex virus $\mathrm{gD}$, represents a major component of the viral envelope and is a dominant immunogen.
To study the antigenic properties of the different regions of $\mathrm{gD}, \mathrm{O} . \mathrm{Y}$. Abdelmagid have expressed the full-length $\mathrm{gD}$ encoding gene and overlapping fragments spanning various regions of the $\mathrm{gD}$ open reading frame in abaculovirus (Autographa californica nuclear polyhedrosis virus) - insect cell (Spodoptera frugiperda, SF-9) system. Maximum levels of expression for all proteins were obtained 48 to $72 \mathrm{~h}$ post infection of SF9 cells by recombinant viruses. Full-length and truncated recombinant $\mathrm{gD}$ proteins reacted specifically with antigD monospecific serum as determined by immune precipitation 
and immunoblotting, indicating that the proteins retained their antigenicity. However, based on the reactivity with a panel of $\mathrm{gD}$ specific monoclonal antibodies (Mabs), the full-length recombinant $\mathrm{gD}$ lacked proper expression for two highly neutralizing linear epitopes identified by Mabs R54 and 9D6. The rest of the epitopes appeared to be preserved and antigenically unaltered. Immunofluorescence studies of recombinant baculovirus infected SF-9 cells using $\mathrm{gD}$ monospecific serum. Revealed no direct correlation between cellular localization of the expressed proteins and their amino acid sequences (Abdelmagid et al., 1998).

At different time interval the total RNA was isolated from BHV -1 infected MDBK cell lines treated with DNase to free genomic DNA contamination of RNA which was used as template in PCR with BHV-1 specific primers there was no amplification in PCR which conformed the RNA was free of BHV1 genomic DNA. This RNA used to pforc DNA synthesis by oligo (dT) primer using MMLV reverse transcriptase at $45 \mathrm{C}$. this cDNA was used for real time PCR with $\mathrm{gD}$ specific $\mathrm{BHV}-1$ primers at $58 \mathrm{C}$ temperature. The objective was to understand the expression profile of $\mathrm{gD}$ gene of $\mathrm{BHV}-1$ virus in MDBK cell line after infection.

The present study reveals novel report on the expression profile of $\mathrm{gD}$ gene at transcript level in BHV-1 infected MDBK cells. gD gene predicted to encode a glycoprotein envelope protein and its expression patterns observed in the current study reveals the importance of this gene in BHV-1 pathogenesis by virtue of their role as virus envelope protein.

However, further studies need to be undertaken to unfold the molecular mechanism of these virus host interactions to be able to design an effective therapy against this dreaded disease of shrimp.

\section{Conflict of Interest}

We certify that there is no conflict of interest with any financial organization regarding the material discussed in the manuscript.

\section{References}

Abdelmagid, O.Y., Mansour, M.M., Okwumabua, O. and Littel-van den Hurk, S.D., 1998. Expression and cellular distribution of baculovirusexpressed bovine herpesvirus 1 (BHV1) glycoprotein $\mathrm{D}$ (gD) sequences. Archives of virology, 143(11), pp.21732187.

Chase, C.C. and Letchworth III, G.J., 1994. Bovine herpesvirus 1 gIV-expressing cells resist virus penetration. Journal of general virology, 75(1), pp.177-181.

Erlich, H.A., Gelfand, D. \& Sninsky, J.J. (1991). Recent advances in the PCR. Science, 252:1643-1651.

Haanes EJ, Thomsen DR, Martin S, Homa FL, Lowery DE (1995) The bovine herpesvirus 1 maturational proteinase and scaffold proteins can substitute for the homologous herpes simplex virus type 1 proteins in the formation of hybrid type B capsids. J Virol 69: 73757379

Kit, S., Qavi, H., Gaines, J.D., Billingsley, P., McConnell, S. (1985). Thymidine kinase negative bovine herpesvirus type 1 mutant is stable and highly attenuated in calves. Arch. Virol., 86: 63-83.

Muylkens B., Meurens F., Schynts F., Farnir F., Pourchet A., Bardiau M., Gogev S., Thiry J., Cuisenaire A., Vanderplasschen A., Thiry E., (2006). Intraspecific bovine herpesvirus 1 recombinants carrying glycoprotein $\mathrm{E}$ deletion as a vaccine marker are virulent in cattle, J. Gen. Virol. 87:2149-2154 
Pershing, D.H. (1991) PCR: trenches to benches. Journal of Clinical Microbiology 29:1285-1291.

Tikoo, S.K., Zamb, T.J. and Babiuk, L.A., 1993. Analysis of bovine herpesvirus 1 glycoprotein gIV truncations and deletions expressed by recombinant
Vaccinia viruses. Journal of virology, 67(4), pp.2103-2109.

Van Drunen Littel-van den Hurk S., (2006). Rationale and perspectives on the success of vaccination against bovine herpesvirus-1, Vet. Microbiol. 113:275282

\section{How to cite this article:}

Asmita Singh and Ajay Kumar. 2018. Expression Profiling of Glycoprotein D Gene of Bovine Herpes Virus in Madindar by Bovine Kidney Cells via Real Time PCR. Int.J.Curr.Microbiol.App.Sci. 7(10): 2807-2816. doi: https://doi.org/10.20546/ijcmas.2018.710.326 